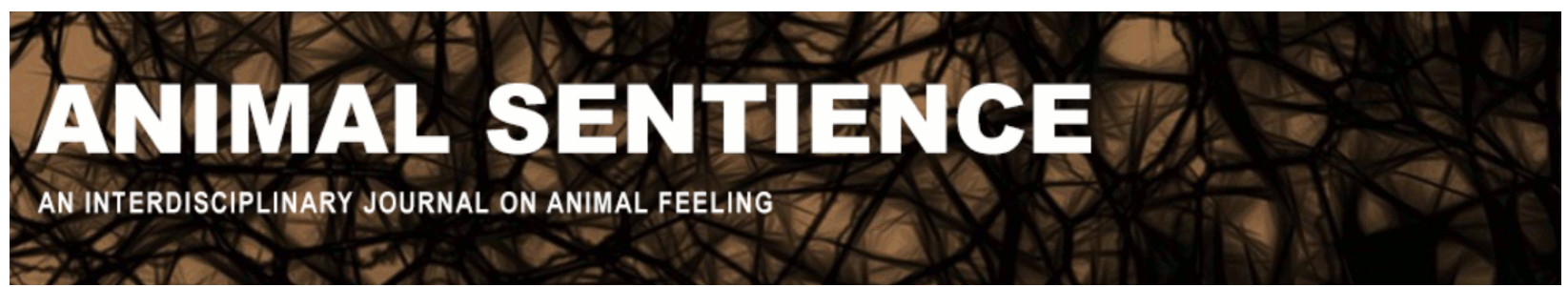

Lamey, Andy (2016) Subjective experience and moral standing. Animal Sentience 9(7)

DOI: $10.51291 / 2377-7478.1136$

Date of submission: 2016-08-05

Date of acceptance: 2016-08-10

(c)

This article has appeared in the journal Animal

Sentience, a peer-reviewed journal on animal

cognition and feeling. It has been made open access,

free for all, by WellBeing International and deposited

in the WBI Studies Repository. For more information,

please contact

wbisr-info@wellbeingintl.org.

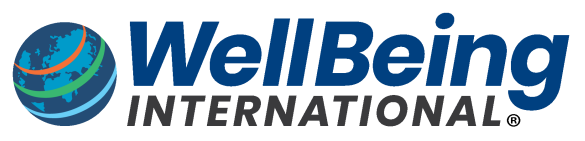

SOLUTIONS FOR PEOPLE, ANIMALS AND ENVIRONMENT 


\title{
Subjective experience and moral standing
}

Commentary on Klein \& Barron on Insect Experience

\author{
Andy Lamey \\ Department of Philosophy \\ University of California, San Diego
}

\begin{abstract}
Klein \& Barron's analysis focuses on the capacity for any subjective experience at all. It does not seek to demonstrate that insects can experience pleasure and pain in particular. This would be something of which insects have not traditionally been thought capable. If further research were to demonstrate that one or more insect species turn out to be conscious, yet incapable of experiencing pleasure and pain, it would give rise to a philosophical question that ethicists have yet to answer: Would a creature that is conscious, but lacks the capacity to feel pain, have moral standing?
\end{abstract}

Andy Lamey is assistant teaching professor at the University of California, San Diego. $\mathrm{He}$ is completing a book, Duty and the Beast: Should We Eat Meat in the Name of Animal Rights? (Cambridge University Press). http://andylamey.com

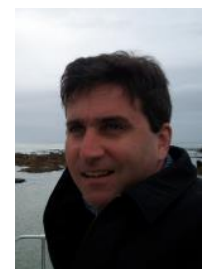

If an individual has moral standing, then how we treat it can be morally significant, independent of how that treatment affects others. A widespread view among animal ethicists is that for an entity to have moral standing, it must be sentient. Animal ethicists have traditionally taken sentience to include the capacity to experience pleasure and pain.

Klein \& Barron (2016) give us a picture of the fast-changing world of insect neuroscience that suggests insects are capable of subjective experience, understood here as being conscious in a minimal sense. They do not try to go on to demonstrate that insects can experience pleasure and pain in particular. This is something of which insects have not traditionally been thought capable (Varner 1998: 53). If insects eventually did turn out to be conscious but incapable of experiencing pleasure and pain, this would raise a philosophical question that ethicists have yet to answer: Does a creature that is conscious, but lacks the capacity to feel pain, have moral standing?

The traditional view of animal sentience was outlined by Peter Singer (1975) in an influential early formulation:

"If a being suffers, there can be no moral justification for refusing to take that suffering into consideration. No matter what the nature of the being, the principle of equality requires that its suffering be counted equally with the like suffering - in so far as rough comparisons can be made - of any other being. If a being is not capable of suffering, or of experiencing enjoyment or happiness, there is nothing to be taken into account. This is why the limit of sentience (using the term as a convenient, if not strictly accurate, shorthand for the capacity to suffer or experience enjoyment or happiness) is the only defensible boundary of concern for the interests of others. To mark this boundary by some characteristic like intelligence or rationality would be to mark it in an arbitrary way. Why not choose some other characteristic, like skin color?" (8-9) 
Singer is careful to note that in his usage, sentience is shorthand for the capacity to experience pleasure or pain (a capacity that presupposes subjective experience). In the rest of his book, however, he does not examine any animals that are thought to be conscious but incapable of experiencing pleasure and pain. Post-Singer, it has been common for animal ethicists to view sentience as a "package deal," involving both subjective experience and the capacity for suffering and enjoyment. If the two attributes can come apart, however, it seems unlikely that the correct response would be to treat merely conscious beings the same way as those that are also capable of suffering. We normally think that causing suffering requires ethical justification. This suggests that the capacity for suffering is morally relevant in its own right. If so, then there are two possible moral views on merely conscious entities. They might not have moral standing at all. Or they might have standing, but to a lesser degree than entities that can suffer.

To say that merely conscious insects lack moral standing would be to deny significance to the fact that there is "something it is like" to be them. This seems hard to accept. Suppose there were a creature that was conscious rather than self-conscious, and was also capable of experiencing pleasure and pain. Now further suppose that it so happened that this creature never actually did suffer or experience pleasure. It never encountered any stimuli that felt good or bad, and its life was lived entirely in a neutral state between the two sensations. If we wanted to (painlessly) euthanize such a creature, would that require justification, or could we end its life simply because we felt like it? To say it would require no justification is to say that its (conscious) life has no moral value.

Intuitively, it seems wrong to think that the contingent absence of pleasure and pain entails that a conscious creature's life would have no moral significance. Surely the creature's subjective experience matters in and of itself. The creature has a centre of consciousness that looks out on the world, a point of view, its own motivations and goals. To treat it as being on the same moral level as a plant or a stone would not take its consciousness into account. Hence if insects did turn out to be merely conscious, it would seem wrong to assign them the same moral status as non-conscious entities.

This brings us to the third possibility: a conscious insect that cannot feel pleasure or pain would possess moral standing, but to a lesser degree than organisms that are sentient in the traditional, package-deal sense. Much as self-conscious entities such as normal adult humans are thought to occupy a degree of moral standing above sentient animals, insects on this view would occupy a new, third level of moral standing beneath animals. Just as we would choose to save a human life at the expense of a dog, all else being equal, we would save a dog at the expense of a merely conscious insect. Yet we would conceivably save the same insect at the expense of a plant or other non-conscious entity, if it were possible to do so without sacrificing any significant interests of our own.

To say that merely conscious insects would occupy a status between sentient animals and plants is not yet to give a precise account of their moral standing. Saying merely conscious insects have level-three standing is as consistent with saying two such insects would outweigh the life of one dog as it is with saying even a thousand insects cannot equal one dog's life. Narrowing the location of merely conscious insects in the range between plants and sentient animals requires going beyond a relative ranking and addressing their moral value in absolute terms.

One way of doing so is suggested by ethical theories that grant weight to the degree of psychological unity a creature has across time: "[T]he degree of psychological unity within a life between times $\mathrm{t} 1$ and $\mathrm{t} 2$ is a function of the proportion of the mental life that is 
sustained over that period, the richness or density of that mental life, and the degree of internal reference among the various earlier and later mental states" (McMahan 2002: 74-5). Fear and hunger are examples of mental states that can be sustained across time. Examples of later mental states that interact with earlier ones include memories and actions that fulfill desires formed much earlier. The greater the overall number of sustaining or interactive mental states, the greater the richness and density of a creature's mental life as a whole.

On this approach, the greater richness and density of the mental lives of self-conscious persons is what grants them higher standing than sentient animals. The death of selfconscious beings matters more because death is a much greater loss for them. Extending this approach to merely conscious insects means that empirical research into the precise nature of their capabilities will have bearing on their moral status. Klein \& Barron ascribe capacities for learning, memory and hunger to insects, but understandably do not say anything about the degree to which these traits are present. This raises the possibility that they are capable of subjective experience and not much else. While we should not rule out surprising discoveries regarding the mental lives of insects, it seems reasonable to place the burden of proof on those who seek to demonstrate that insects have memory and similar traits to a more than minimal degree. If we stick with such a minimalist picture, it implies that death would be an extremely small deprivation for merely conscious insects because ascribing them subjective experience and little else does not entail any significant degree of psychological unity.

Merely conscious insects that lacked the capacity to experience pleasure and pain would have some interest in continued existence, but this would be so minor that it would easily be outweighed by human interests when the two come in conflict. In practical terms, if there is a mosquito buzzing around inside my house, rather than kill it, I should take the trouble to let it out the door when I can easily do so; but if the same mosquito lands on my arm my interest in not being bit will justify killing it.

This view is compatible with the traditional one that insects barely matter on a moral level. Science and philosophy do not always combine to preserve our pre-reflective views, however. We cannot rule out in advance the possibility that science may one day show that insects have psychological continuity in a not-so-minimal sense. They may even turn out to feel pleasure and pain. If that day comes, a principled rationale for continuing to assign insects a negligible moral status will be hard to find.

\section{References}

Klein, C., \& Barron, A. B. (2016). Insects have the capacity for subjective experience. Animal Sentience 2016.100.

McMahan, J. (2003). The Ethics of Killing: Problems at the Margins of Life. New York: Oxford University Press.

Singer, P. (1975). Animal Liberation. New York: Avon.

Varner, G. (1998). In Nature's Interest: Animal Rights and Environmental Ethics. Oxford University Press: Oxford. 